\title{
Blockade of glutamate release by botulinum neurotoxin type $A$ in humans: A dermal microdialysis study
}

\author{
Larissa Bittencourt da Silva BSc ${ }^{1}$, Ali Karshenas MD², Flemming W Bach MD DMSc ${ }^{2}$, Sten Rasmussen MD $^{3}$, \\ Lars Arendt-Nielsen PhD DMSc ${ }^{1}$, Parisa Gazerani PharmD PhD ${ }^{1}$
}

\begin{abstract}
L Bittencourt da Silva, A Karshenas, FW Bach, S Rasmussen, L Arendt-Nielsen, P Gazerani. Blockade of glutamate release by botulinum neurotoxin type $\mathrm{A}$ in humans: A dermal microdialysis study. Pain Res Manag 2014;19(3):126-132.
\end{abstract}

BACKGROUND: The analgesic action of botulinum neurotoxin type A (BoNTA) has been linked to the blockade of peripheral release of neuropeptides and neurotransmitters in animal models; however, there is no direct evidence of this in humans.

OBJECTIVES: To investigate the effect of BoNTA on glutamate release in humans, using an experimental model of pain and sensitization provoked by capsaicin plus mild heat.

METHODS: Twelve healthy volunteers (six men, six women) were pretreated with BoNTA (10 U) on the volar forearm and with a saline control on the contralateral side. Dermal microdialysis was applied one week later to collect interstitial samples before and after the application of a capsaicin patch $(8 \%)$ plus mild heat $\left(40^{\circ} \mathrm{C} / 60 \mathrm{~min}\right)$ to provoke glutamate release, pain and vasodilation. Samples were collected every hour for $3 \mathrm{~h}$ using linear microdialysis probes $(10 \mathrm{~mm}, 100 \mathrm{kD})$. Dialysate was analyzed for glutamate concentration. Pain intensity and skin vasomotor reactions (temperature and blood flow changes) were also recorded.

RESULTS: BoNTA significantly reduced glutamate release compared with saline $(\mathrm{P}<0.05)$. The provoked pain intensity was lower in the BoNTA-pretreated arm $(\mathrm{P}<0.01)$. The reduction in pain scores was not correlated with glutamate level. Cutaneous blood flow $(\mathrm{P}<0.05)$, but not cutaneous temperature $(\mathrm{P} \geq 0.05)$, was significantly reduced by BoNTA. There was a correlation between glutamate level and skin blood flow $(r=0.58 / \mathrm{P}<0.05)$ but not skin temperature $(\mathrm{P} \geq 0.05)$. No differences according to sex were observed in any response.

CONCLUSIONS: The present study provided the first direct evidence supporting the inhibitory effect of BoNTA on glutamate release in human skin, which is potentially responsible for some of the analgesic action of BoNTA.

Key Words: Botulinum neurotoxin type A; Capsaicin; Glutamate; Human experimental pain model; Microdialysis; Vasodilation

\section{Le blocage de la libération du glutamate par la neurotoxine botulique de type A chez les humains : une étude de microdialyse cutanée}

HISTORIQUE : L'action analgésique de la neurotoxine botulique de type A (NBdTA) est liée au blocage de la libération périphérique des neuropeptides et des neurotransmetteurs. Cependant, il n'y en a pas de preuves directes chez les humains.

OBJECTIFS : Examiner l'effet de la NBdTA sur la libération du glutamate chez les humains, au moyen d'un modèle expérimental de douleur et de sensibilisation provoquées par la capsaïcine et une chaleur légère.

MÉTHODOLOGIE : Douze volontaires en bonne santé (six hommes, six femmes) ont reçu un traitement préalable à la NBdTA (10 U) sur l'aspect antérieur de l'avant-bras et une injection de soluté physiologique du côté controlatéral. La microdialyse cutanée a été appliquée une semaine plus tard pour recueillir des échantillons interstitiels avant et après l'application d'un timbre de capsaïcine $(8 \%)$ associé à une chaleur légère $\left(40^{\circ} \mathrm{C}\right.$ pendant 60 minutes) pour provoquer une libération de glutamate, de la douleur et une vasodilatation. Les échantillons ont été recueillis toutes les heures pendant trois heures au moyen de sondes pour microdialyse linéaire (10 mm, $100 \mathrm{kD})$. Le dialysat a été analysé pour déterminer la concentration de glutamate. L'intensité de la douleur et les réactions vasomotrices cutanées (températures et modifications du débit sanguin) ont également été enregistrées.

RÉSULTATS : La NBdTA réduit la libération de glutamate beaucoup plus que le soluté physiologique $(\mathrm{P}<0,05)$. L'intensité de la douleur provoquée était plus faible dans le bras prétraité par NBdTA $(\mathrm{P}<0,01)$. La réduction des indices de douleur n'était pas corrélée avec le taux de glutamate. La NBdTA réduisait considérablement le débit sanguin cutané $(P<0,05)$, mais pas la température cutanée $(\mathrm{P} \geq 0,05)$. Il y avait une corrélation entre le taux de glutamate et le débit sanguin cutané $(r=0,58 / \mathrm{P}<0,05)$, mais pas la température cutanée $(P \geq 0,05)$. Aucune des réponses ne comportait de différence en fonction du sexe.

CONCLUSIONS : La présente étude a fourni les premières preuves directes de l'effet inhibiteur de la NBdTA sur la libération de glutamate sur la peau humaine, potentiellement responsable de l'action analgésique de la NBdTA.

pain (9-11), low back pain (12), myofascial pain $(13,14)$, fibromyalgia (15), trigeminal neuralgia (16), postherpetic neuralgia (17), headaches (18) and migraine $(19,20)$. Although BoNTA is effective in several pain conditions, as mentioned above, migraine is the only approved condition, while the remaining conditions continue to be treated off-label. Most of the proposed mechanisms underlying analgesic effects of the toxin are based on in vivo animal models $(8,21$ 23) and in vitro culture systems (24-29), which have shown that BoNTA is able to suppress the local release of substances involved in pain and vasodilation including glutamate (23), substance $\mathrm{P}$ (SP) $(21,25)$ and calcitonin gene-related peptide (CGRP) (29). It has been suggested that this phenomenon may contribute to the pain studies involving animals and humans (6-8). BoNTA has been found to be efficient in painful conditions including neuropathic

${ }^{1}$ Center for Sensory-Motor Interaction, Department of Health Science and Technology, Faculty of Medicine, Aalborg University; ${ }^{2}$ Department of Neurology, Aalborg University Hospital; ${ }^{3}$ Orthopaedic Surgery Research Unit, Aalborg Hospital Science and Innovation Center, Aalborg University Hospital, Aalborg, Denmark

Correspondence: Dr Parisa Gazerani, Center for Sensory-Motor Interaction, Department of Health Science and Technology, Faculty of Medicine, Aalborg University, Fredrik Bajers Vej 7-D3, DK-9220 Aalborg, Denmark. Telephone 45-99-40-24-12,

fax 45-98-15-40-08, e-mail gazerani@hst.aau.dk 


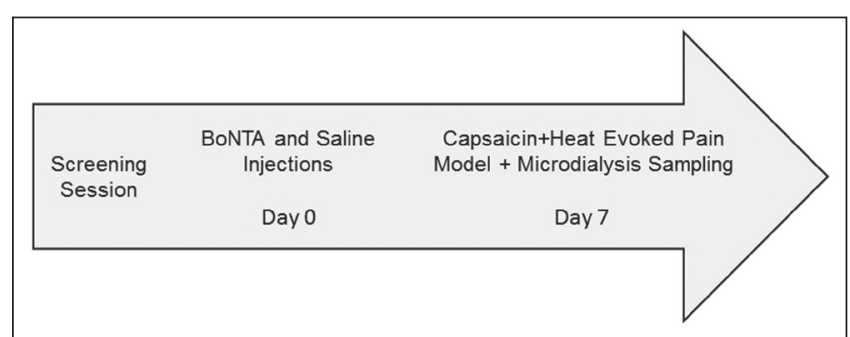

Figure 1) Simplified experimental design showing the time course of all sessions performed. After a screening session, subjects attended a botulinum neurotoxin type A (BoNTA) and control pretreatment session. After seven days, the experimental session was completed

inhibition of peripheral sensitization and pain and, possibly, prevent central sensitization $(27,30)$.

Glutamate is a well-known excitatory neurotransmitter with an important mediatory and modulatory role in nociception and sensitization $(31,32)$. It has been previously shown that activation of peripheral glutamate receptors contributes to nociception and peripheral sensitization (33-35). Moreover, an increased glutamate level is known to be involved in a number of painful conditions such as migraine and fibromyalgia $(36,37)$. Blockade of glutamate release by BoNTA has only been investigated in animal models, and there is no evidence regarding whether similar phenomenon would occur in humans following pretreatment with BoNTA. Therefore, the present study investigated this in humans using dermal microdialysis.

The microdialysis technique has long being used to examine metabolic changes or dynamic patterns of substance release (eg, glutamate $[38,39])$ in different tissues under physiological or pathological conditions (40-42). Previously, it has been shown that capsaicin stimulation provokes release of glutamate from primary afferent fibres in rats (43). Thus, we designed an experimental model of pain evoked by capsaicin plus mild heat in healthy volunteers to provoke glutamate release and to further investigate potential inhibitory action of BoNTA on glutamate release in humans.

We hypothesized that intradermal injection of BoNTA alters the release of glutamate in human skin. The aims of the present study were: to investigate glutamate release following application of a topical capsaicin patch $(8 \%)$ plus mild heat; and to examine the effect of BoNTA on the evoked pain and vasomotor responses (temperature and blood flow) and glutamate release. The present study is the first to apply microdialysis to directly investigate the inhibitory effect of BoNTA on glutamate release in human skin.

\section{METHODS}

\section{Subjects}

The group of healthy volunteers consisted of six men (mean [ \pm SEM] age $25.0 \pm 1.5$ years) and six women (mean age $25.7 \pm 0.72$ years), who were recruited among students through advertisements at Aalborg University, Aalborg, Denmark. Participants were informed about the experimental procedures, safety issues, goals and perspectives of the research and provided written informed consent before the start of the experiments.

\section{Study design}

The study was designed as a double-blinded, randomized, placebocontrolled trial, and was approved by the local ethics committee (Region of North Jutland, Denmark; N-20110075) and the Danish data protection agency. Good Clinical Practice guidelines and the Declaration of Helsinki were followed during the course of the study. Participants attended three sessions in total. The first session consisted of a screening session, at which medical history was reviewed and the subject was excluded if any previous or present skin, systemic or neuromuscular diseases were present including migraine or chronic tensiontype headache, diabetes, peripheral neuropathies, fibromyalgia,

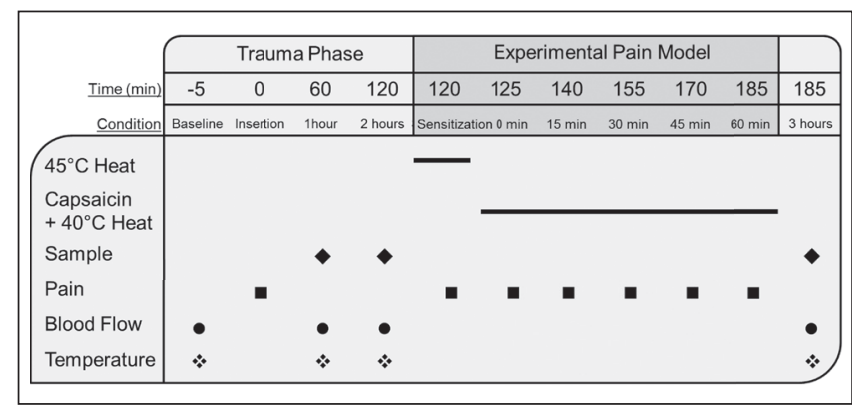

Figure 2) Schematic diagram showing the timeline, interventions and measurements performed throughout the experimental session. Along with a time frame, a line with the condition is outlined to match all nomenclature of the events. The baseline represents the measurement before the probe insertion, followed by $2 \mathrm{~h}$ during which no intervention was performed, referred to as the trauma phase. Subsequently, sensitization stimuli with $45^{\circ} \mathrm{C}$ heat for 5 min was performed before the capsaicin $+40^{\circ} \mathrm{C}$ heat treatment, which lasted $1 \mathrm{~h}$. Apart from the two heat stimulations, a total of four measurements were made throughout the experiment: sample collection, pain ratings, skin blood flow and skin temperature

myasthenia gravis, Lambert-Eaton syndrome, amyotrophic lateral sclerosis or any other significant disease that may interfere with neuromuscular function. In addition, they could not participate if they had any severe allergy or history of current or past alcohol and/or drug abuse. Female volunteers were not pregnant or experiencing irregularities in their menstrual cycles. They could not be taking any medication during the sessions, nor could they be participating in another experiment. Weight and height were measured, and only participants with body mass index between $19 \mathrm{~kg} / \mathrm{m}^{2}$ and $35 \mathrm{~kg} / \mathrm{m}^{2}$ were included. In the screening session, a challenge using the capsaicin pain model was also performed to evoke pain and flare. Only subjects who rated pain intensity $>5$ (on a visual analogue scale ranging from 0 to 10) and developed a visible flare in response to this challenge were included in the present study. Individuals who passed the screening session were scheduled for the experimental sessions, at which they first received BoNTA and saline (control) injection in each forearm in a randomized, blinded fashion; the physician who injected BoNTA and saline did not know the content of the syringes and the investigator did not receive the code until the end of the trial. The subjects also did not know which arm was pretreated with the toxin or the vehicle, which was also randomized. All safety precautions were taken during the injections. After a one-week interval, which has been shown to be the peak of the toxin's analgesic effect in the authors' previous experimental pain models in humans $(7,44,45)$, subjects were challenged using a topical capsaicin patch $(8 \%)$ plus mild heat while a microdialysis membrane was placed on the pretreated area. They were asked to refrain from ingesting chili peppers $48 \mathrm{~h}$ before and caffeinecontaining products $24 \mathrm{~h}$ before the experimental session. During the study sessions, each volunteer rested in a supine position. An overview of the study design is presented in Figure 1. Sensory and vasomotor assessments performed for each experimental session are summarized in Figure 2. The same investigator (LBS) performed all of the tests at the pain laboratory, a quiet environment with a controlled temperature of $22^{\circ} \mathrm{C}$ to $23^{\circ} \mathrm{C}$ located in the Center for Sensory-Motor Interaction, Aalborg University, Denmark.

\section{BoNTA and saline injections}

Each vial of BoNTA (BOTOX ${ }^{\circledR}$, Allergan Incorporated, USA) was reconstituted using preservative-free $0.9 \%$ sodium chloride. Each participant received a single injection of BOTOX $(10 \mathrm{U} / 0.2 \mathrm{~mL})$ using a disposable needle (Neuroline Inoject, 27 gauge, Ambu A/S, Denmark) intradermally in the volar part of the forearm, $5 \mathrm{~cm}$ distant from the cubital fossa, as shown in Figure 3. An equal volume of sterile physiological saline $(0.2 \mathrm{~mL}, 0.9 \%)$ was injected in the contralateral forearm as a control. The injection side was randomized and blinded. The 


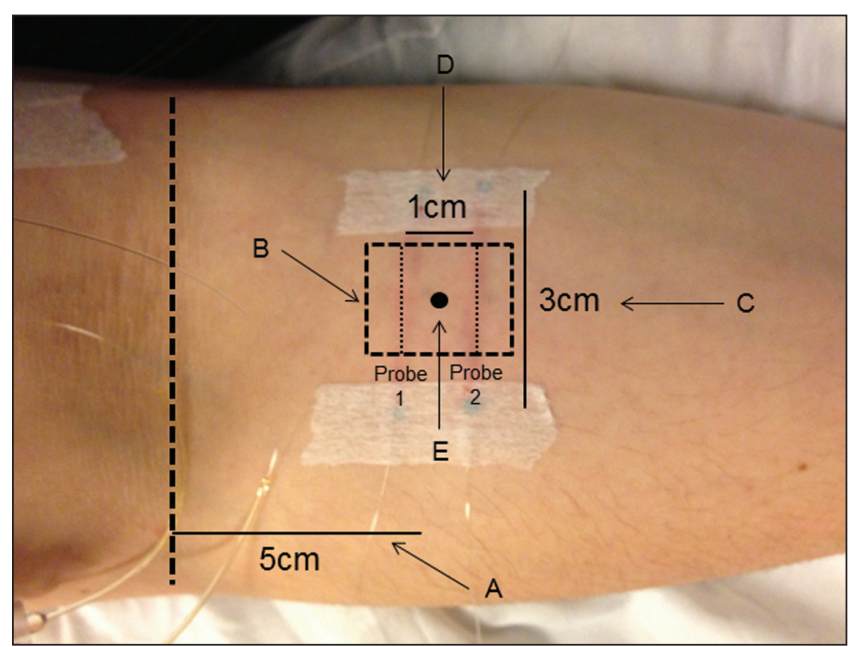

Figure 3) Arrows indicate: A distance between the cubital fossa and the botulinum neurotoxin type A (BoNTA) injection point $(5 \mathrm{~cm})$; B capsaicin patch application covering probe 1 and 2; $\mathrm{C}$ distance between probes inlet and outlet $(3 \mathrm{~cm}) ; \mathrm{D}$ distance between probe 1 and $2(1 \mathrm{~cm}) ; \mathrm{E}$ BoNTA and saline injection point. The figure shows the schematic of the region of interest for all interventions. BoNTA (10 U) and control pretreatment injections (E) were made approximately $5 \mathrm{~cm}$ away from the cubital fossa (A). The guided needle was inserted across the skin for $3 \mathrm{~cm}(\mathrm{C})$ to facilitate the insertion of the probes, which were inserted $1 \mathrm{~cm}$ apart from one another (D) with the pretreated site in the middle. The capsaicin patch was placed so that it covered both probes (B)

injection sites were mapped on a transparent sheet for further location tracking during the microdialysis membrane insertion.

\section{Microdialysis}

Two clinically approved, sterile, single-use microdialysis membranes for human use were inserted in each arm (66 High Cut Off Linear Microdialysis Catheter, 100 kD cut-off, M Dialysis AB, Sweden). The two membranes were inserted $1 \mathrm{~cm}$ from the pretreatment injection site (BoNTA and saline injections), with one on each side. For each membrane, a needle was inserted intradermally along $3 \mathrm{~cm}$ to introduce the catheter, this being placed in the middle with $1 \mathrm{~cm}$ left intact from both sides. With the membrane in place, the needle was withdrawn and the inlet and outlet were secured with a hypoallergenic paper tape (Micropore tape, 3M, USA), as shown in detail in Figure 3. Afterwards, both membranes were connected to microdialysis pumps (107 MD Pump, M Dialysis AB, Sweden). The 107 MD is an adjustable pump and was set to $3 \mu \mathrm{L} / \mathrm{min}$ and perfused with a sterile and isotonic fluid (Perfusion Fluid T1, M Dialysis AB, Sweden). Samples $(n=6)$ were collected every hour for a maximum of $3 \mathrm{~h}$. Although the microdialysis technique is considered to be a minimally invasive method, the probe insertion in the upper dermis layer is painful and can trigger a substantial inflammatory response. Therefore, the targeted tissue needs time to recover from the needle perfusion injury. To allow the tissue to recover from the insertion trauma, a period of $2 \mathrm{~h}$ was given, as recommended $(46,47)$. The recovery of the experimental system was evaluated in preliminary trials in human skin with the same probe and pump, and at a similar flow rate.

\section{Capsaicin + mild heat-evoked pain model}

Before the application of the capsaicin patch, the area was presensitized with heat stimulation at $45^{\circ} \mathrm{C}$ for $5 \mathrm{~min}$. Capsaicin patch $8 \%$ (Qutenza ${ }^{\circledR}$, Astellas Pharma Europe Ltd.) was then applied to evoke pain and flare. The patch size was $6 \mathrm{~cm}^{2}$ (3.84 $\mathrm{mg}$ of capsaicin) and was placed on the BoNTA- and saline-pretreated areas for $1 \mathrm{~h}$ along with mild heat $\left(40^{\circ} \mathrm{C}\right)$ delivered using the PATHWAY ATS advanced thermal stimulator (Medoc Ltd, Israel) through the thermode $(30 \mathrm{~mm}$ $\times 30 \mathrm{~mm}$ ), avoiding the microdialysis membrane.

\section{Microdialysis samples}

Samples from all subjects were collected and included in the analysis. Samples were stored at $-80^{\circ} \mathrm{C}$ for later analysis.

\section{Measurement of glutamate}

Samples $(10 \mu \mathrm{L})$ were analyzed for their glutamate content and investigation of pattern change over the time-course of the trial. An ISCUSflex Microdialysis Analyzer (M Dialysis AB, Sweden) was used, which applies enzymatic reagents and colorimetric measurements to monitor a number of different substances including glutamate. The results are presented in $\mu \mathrm{M}$, as a comparison between the BoNTA- and saline-pretreated sides.

\section{Capsaicin + mild heat-evoked pain}

Pain scores were recorded after the membrane insertion, following the heat sensitization period and every $15 \mathrm{~min}$ from the capsaicin patch application. Subjects were asked to rate their pain intensity on a visual analogue scale, on which $0=$ 'no pain' and $10=$ 'the most pain imaginable'. The peak pain intensity scores were manually recorded and used for statistical analysis.

\section{Skin blood flow}

Skin blood flow was measured using a laser speckle contrast imager (FLPI, Moor Instruments, United Kingdom) to monitor vasomotor changes in the treated area. This device uses a full-field laser technique and provides real-time and high-resolution images of blood flow. The technique is noninvasive and is based on a random speckle pattern that is generated when tissue is illuminated by the laser light to capture the movement of the blood cells. With the lenses placed $40 \mathrm{~cm}$ perpendicularly above the tissue, it was possible to obtain an image of the entire forearm at baseline, and every hour after the membrane insertion, up to $3 \mathrm{~h}$. To better follow the magnitude of the blood flow changes, an area of approximately $9 \mathrm{~cm}^{2}$ was later chosen as a region of interest (ROI) for the analysis, which comprised the patch surface along with the surrounding area. The software was set to capture pictures using high resolution/low speed with $1 \mathrm{~s}$ per frame in a free-run mode. An 8 ms exposure time was selected. The images were stored on the computer's hard disk for offline analysis. The average blood flow within the ROI was calculated using the designated Moor software (mFLPIV4, Moor Instruments), expressed in arbitrary units and used for statistical analysis. Measurements were performed in a semidark room to eliminate artifacts from ambient room lighting.

\section{Skin temperature}

Skin temperature was assessed using a noninvasive infrared thermographic camera (FLIR Systems Inc, Sweden) to record the surface tissue temperature changes. The temperature resolution of the device is $0.09^{\circ} \mathrm{C}$. The distance between the lenses and the tissue surface was set to $50 \mathrm{~cm}$ to capture the entire forearm image in a single frame. Measurements were performed before the membrane insertion (baseline) and every hour for $3 \mathrm{~h}$ after the insertion. While the baseline measurement was performed with the intact and uncovered skin, the subsequent measurements were taken after probe insertion or placement of the patch on the cannulated area. To obtain the profile and magnitude of temperature changes, a square ROI (approximately $9 \mathrm{~cm}^{2}$ ) was defined that comprised the patch surface and the surrounding area. Thermographic images were stored on the computer's hard disk for offline analysis. The average temperature within the ROI was calculated by ThermaCAM researcher Pro 2.8 (FLIR Systems Inc) and used for statistical analysis. To eliminate artifact from ambient room lighting, measurements were performed in a semidark room.

\section{Statistical analysis}

The number of participants was estimated using the formula $\mathrm{n}=\left(\left[2 \times \mathrm{SD}^{2}\right] / \mathrm{E}^{2}\right) \times \mathrm{k}$, where $\mathrm{k}$ was 7.9 constant value, $\alpha$ was set to 0.05 (corresponding to a significance level of $\mathrm{P}<0.05$ ) and $\beta$ was set to $20 \%$, corresponding to a statistical power of 0.8 (48). E and SD are the minimal clinically relevant difference between the two situations (BoNTA 


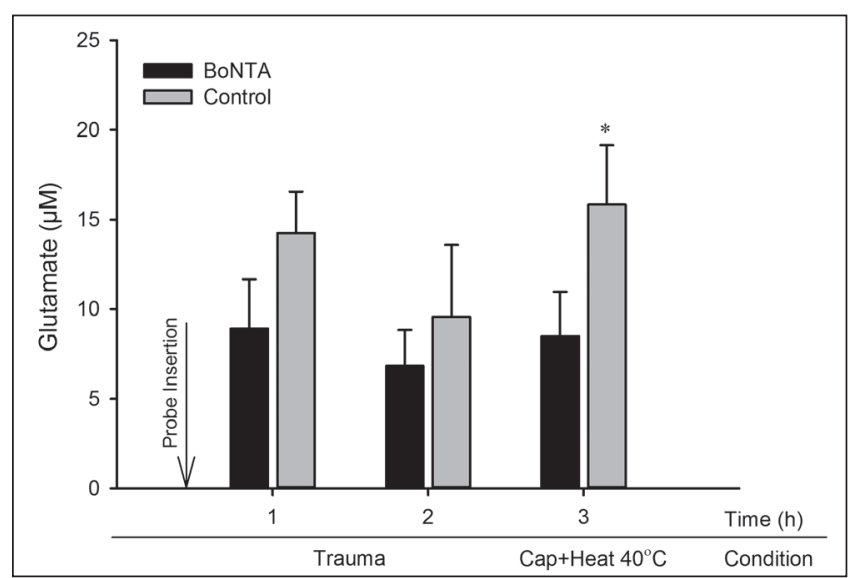

Figure 4) Microdialysis samples were collected $1 \mathrm{~h}$ and $2 \mathrm{~h}$ following probe insertion (trauma phase) and after sensitization and capsaicin (cap) $+40^{\circ} \mathrm{C}$ heat (experimental pain model stimulation) to follow the pattern of glutamate release from the botulinum neurotoxin type A (BoNTA) and control sides. The graph shows mean and SEM. $* P<0.05$

versus saline) and the SD of the mean difference between the two, respectively. For a better estimation, data from a previous study (42) were used, in which E (for CGRP) was found to be 2.04 (as expected to yield a difference of $30 \%$ ) and SD was found to be 1.7 in a microdialysis study involving human skin. Applying these, the number of participants was calculated to be $\mathrm{n}=10.97$. Therefore, 12 subjects were recruited to have sufficient number to detect a possible suppressive effect of BoNTA in the current study.

Data are presented as mean and SEM in the text and figures, unless otherwise specified. Data were analyzed using ANOVA with three factors, defined as: treatment (BoNTA and saline), time (baseline and different time points) and sex (male and female). The Bonferroni test was used for post hoc analysis. All statistical tests were performed using SPSS version 20 (IBM Corporation, USA); $\mathrm{P}<0.05$ was considered to be statistically significant.

\section{RESULTS}

All volunteers completed the study and no safety issues were reported. The main findings were: that BoNTA showed a significant inhibitory effect on glutamate release in the skin; and that BoNTA reduced capsaicin + mild heat-evoked pain intensity and skin blood flow. None of the observed responses were sex dependent.

\section{Glutamate concentration}

Pretreatment with BoNTA significantly reduced capsaicin + mild heat-evoked glutamate release compared with saline $(\mathrm{F}=5.028$; $\mathrm{P}<0.05$ ), as shown in Figure 4. Furthermore, post hoc analysis revealed a significant interaction between treatment and time in the levels of glutamate release in the final samples collected following the capsaicin + mild heat-evoked pain stimulation $(\mathrm{F}=7.974 ; \mathrm{P}<0.05)$.

\section{Pain characteristics}

Capsaicin + mild heat-evoked pain intensity was lower in the BoNTA-pretreated arm $(\mathrm{F}=9.894 ; \mathrm{P}<0.01)$. Moreover, post hoc analysis showed a significant interaction between treatment and time, revealing higher pain ratings $(\mathrm{F}=8.670 ; \mathrm{P}<0.05)$ during the sensitization period, before the membrane insertion and $60 \mathrm{~min}$ after the capsaicin + heat stimulation, with the BoNTA-pretreated side showing lower ratings compared with saline. Detailed information is presented in Figure 5.

\section{Skin blood flow}

The elevated skin blood flow evoked by capsaicin + mild heat was significantly attenuated by BoNTA $(\mathrm{F}=5.822 ; \mathrm{P}<0.05)$ compared with saline. Post hoc analysis showed a significant interaction between

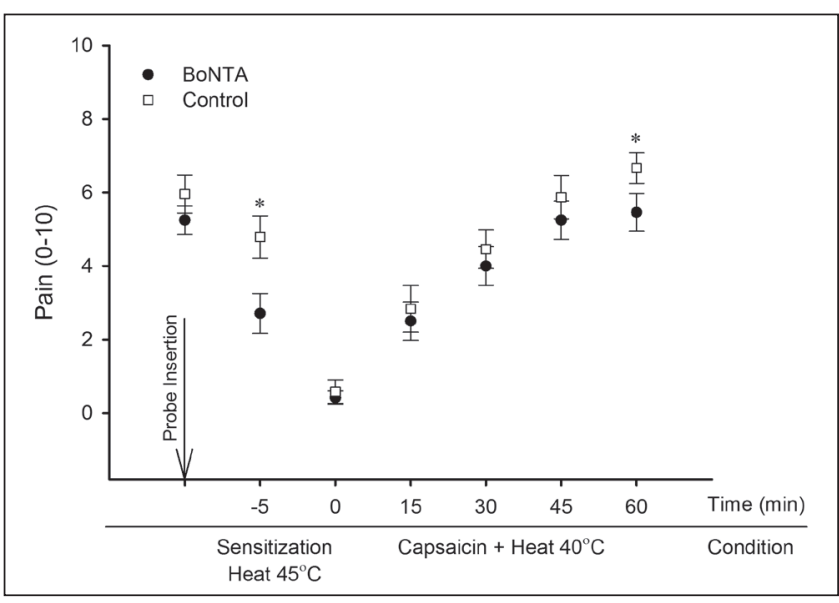

Figure 5) Peak pain was recorded at the probe insertion, sensitization period $\left(45^{\circ} \mathrm{C}\right.$ heat for $\left.5 \mathrm{~min}\right)$ and every $15 \mathrm{~min}$ for $1 \mathrm{~h}$ after the capsaicin and $40^{\circ} \mathrm{C}$ heat application. Subjects rated the pain on a visual analogue scale from 0 to 10, on which 0 represents 'no pain' and 10 'the maximum pain imaginable'. The graph shows mean and SEM; $* P<0.05$

treatment time; the response was greatest $3 \mathrm{~h}$ after the membrane insertion $(\mathrm{F}=7.113 ; \mathrm{P}<0.05)$, as shown in Figure 6.

\section{Skin temperature}

No significant difference was observed in the skin temperature measurements between BoNTA- and saline-pretreated areas $(\mathrm{F}=0.008$; $\mathrm{P} \geq 0.05$ ).

\section{Correlation}

When comparing all outcomes, a correlation was found between the glutamate levels and blood flow $(\mathrm{r}=0.58 ; \mathrm{P}<0.05)$. This correlation showed that blood flow was higher with higher levels of glutamate. All other outcomes did not reveal any correlation.

\section{DISCUSSION}

The present study examined glutamate release following cutaneous human experimental pain provoked by capsaicin + mild heat before and after localized BoNTA treatment. BoNTA decreased pain intensity, suppressed the capsaicin-evoked elevated skin blood flow and lowered the release of glutamate. These responses were sex-independent. This is the first evidence in humans to show that BoNTA attenuates glutamate release in the skin and is consistent with previous findings in animals. The blockade of glutamate release may contribute to the peripheral analgesic effects of BoNTA.

\section{The effect of BoNTA on glutamate release}

Glutamate is one of the most important excitatory neurotransmitters involved in pain transmission, both in the central nervous system and in the periphery. Evidence shows that an increased level of glutamate is found in inflammatory disease and pain conditions, such as myalgia (49), temporal mandibular disorder (39) and chronic tendinitis (41), all measured using the microdialysis technique, which enables the collection of fluid samples from the interstitial space of targeted tissues through a permeable membrane. Protein-unbound molecules move freely from one side of the membrane to the other, based on the concentration gradient of these substances $(38,50)$.

In the present study, we used a capsaicin patch $(8 \%)$ plus mild heat as a pain model, which is known to activate polymodal mechanoheat receptors located on nociceptive primary C-fibres $(51,52)$. This activation leads to sensitization and local release of neurotransmitters, such as glutamate, CGRP and SP, from the peripheral nerve endings $(51,52)$. Here, we demonstrated that provoked glutamate release by this pain model was attenuated by BoNTA. In a previous study by our group, BoNTA decreased glutamate concentration in the temporalis 


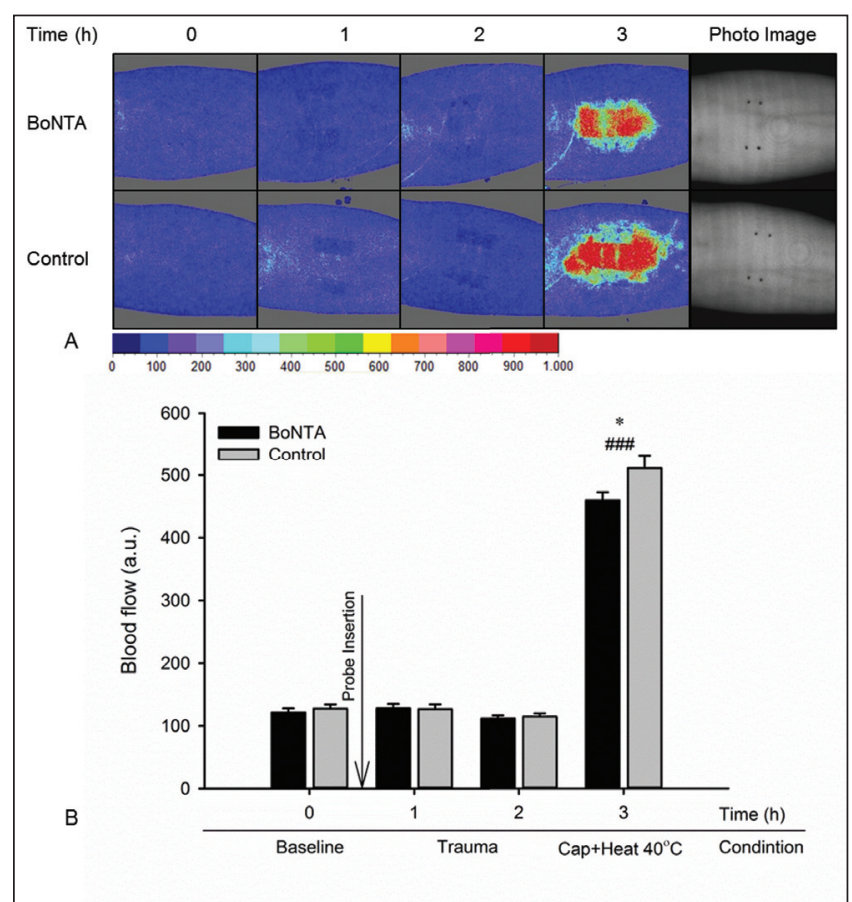

Figure 6) A Typical blood flow image at baseline, $1 \mathrm{~h}$ and $2 \mathrm{~h}$ after probe insertion, and after sensitization and capsaicin (cap) $+40^{\circ} \mathrm{C}$ heat stimulation, shown with a corresponding image of the region of interest. The upper sequence shows the botulinum neurotoxin type A (BoNTA)-pretreated side and the lower sequence shows the matching control. B Blood flow was measured before probe insertion (baseline) and every hour for $3 \mathrm{~h}$. Assessments were made in each arm (BoNTA and control). The graph shows mean and SEM; $* P<0.05$. BoNTA versus control; \#\# $P<0.001,2 \mathrm{~h}$ timepoint versus capsaicin $+40^{\circ} \mathrm{C}$ heat. A correlation was found between the level of glutamate release and blood flow $(r=0.58 ; P<0.05)$. au Arbitratry units

muscle of rats more rapidly and to a greater extent compared with saline (53). This effect has also been shown in an animal model of formalin-induced pain, in which rats were pretreated with BoNTA and challenged with formalin in the paw. Application of BoNTA five days before formalin-induced pain led to a significant decrease in glutamate release (23). In preclinical settings, it has been shown that substance release is blocked by BoNTA through cleavage of synaptosomalassociated protein $25(54,55)$. Based on our observation and some previous animal data, it is likely that BoNTA may also influence the release of other substances, such as CGRP and SP, from the primary afferent neurons. Thus, microdialysis may prove useful for further discoveries and for recording dynamic patterns of substance release (eg, CGRP, SP) following BoNTA treatment in human tissue in vivo. In rats, it has been shown that some endogenous analgesic compounds are elevated following BoNTA administration (56); whether enkephalin, endorphin and/or dynorphin levels are modulated by BoNTA in humans, and whether these changes are detectable by microdialysis, remains unknown.

\section{The effect of BoNTA on evoked pain}

The capsaicin patch (8\%) plus mild heat applied in the present study was found to be a reliable pain model to induce pain and vasomotor responses. Capsaicin-sensitive neurons release several neuropeptides, such as SP, neurokinin A, somatostatin and CGRP, some of which are known to be involved in pain induction and transmission (57). It is also known that glutamate receptors, which are present on the primary afferent neurons, can be activated by glutamate and provoke pain in both animals and humans $(35,58)$.

The inhibitory effect of BoNTA on glutamate release has not only been shown in formalin-induced pain in the hind paws of rats (23), but also in rat trigeminal nerve cells (29), rabbit iris sphincter and dilator muscles (21), and embryonic rat dorsal root ganglia neurons (25). Moreover, several animal and human studies have demonstrated an analgesic effect of BoNTA $(6-8,45,53)$, while others have not (5963). Differences among studies could be due to various reasons. For example, the inconsistency of the botulinum toxin types used may be one factor. Differences in doses (in units), sites of application (muscle or skin), methodology of BoNTA administration, assessment techniques and outcome parameters may also lead to these contradictions. In addition, the experimental pain models used in each of these studies differ to a large extent. Voller et al (59) used capsaicin-induced pain and Krämer et al (63) used electrical-induced pain, while Sycha et al (61) used an experimental ultraviolet B pain model.

In the present study, pretreatment with BoNTA significantly reduced pain and demonstrated an antinociceptive effect of BoNTA on the peripheral nociceptors sensitized by capsaicin and mild heat. These results confirm the suitability of the chosen model. Because we measured glutamate levels in parallel with pain responses, we were interested to determine whether these two parameters are correlated; however, the results did not indicate a correlation. Therefore, it is assumed that glutamate release inhibition is only partially responsible for the analgesic action of BoNTA and other factors/substances are potentially involved.

\section{The effect of BoNTA on vasomotor responses}

Capsaicin provokes neurogenic inflammation. This flare can be attributed to neuropeptides (eg, CGRP and, to some extent, SP) released from peripheral nerve endings (64). These substances are released from primary afferents (65). It has been shown that SP is colocalized in primary afferent terminals with CGRP and glutamate (66). CGRP is a potent vasodilator affecting precapillary arterioles, and SP enhances vascular permeability by acting on capillaries and postcapillary venules. These substances are involved in the physiological control of blood flow $(52,67-69)$. It is believed that the $40^{\circ} \mathrm{C}$ heat stimulation would enhance these reactions (neuropeptide release and vasodilation) through the same receptor involved in the capsaicin reaction (transient receptor potential cation channel subfamily $V$ member 1 [TRPV1]), in addition to the TRPV3 receptor (which is insensitive to capsaicin). The latter is known to be present on the primary afferent fibres in the skin and is sensitive to heat stimulation $>39^{\circ} \mathrm{C}(70)$. Consistent neurogenic inflammation was found in the present study, and BoNTA reduced the provoked blood flow, as previously observed $(7,45)$. On the contrary, no temperature change by BoNTA was detected, which may be a result of the interference in the irradiated heat while the patch was placed on the skin for the final measurement. The plastic-based patch may affect the exact temperature or correct recording due to its different composition compared with the skin. Moreover, a linear association has not always been drawn between temperature and blood flow measurements (71). Considering all of these limitations, the blood flow reduction by BoNTA adds further support to the concept that skin blood flow is a reliable parameter and could be used as an element to monitor some aspects of analgesic efficacy in specific candidate compounds. A correlation was found between the reduction of glutamate release and blood flow changes following BoNTA pretreatment, supporting the contribution of glutamate in cutaneous vasodilation in human skin and the inhibitory role of BoNTA. To determine the role of CGRP and SP and potential inhibitory effect of BoNTA, further investigation is required to measure the levels of these substances along with glutamate levels using the method described in the current study.

\section{CONCLUSIONS}

The present study demonstrated that BoNTA attenuated the release of glutamate in human skin when provoked by capsaicin + mild heat stimulation. BoNTA inhibited the provoked pain and reduced the blood flow. An association was found between BoNTA reduction in glutamate release and provoked blood flow response. 
ACKNOWLEDGEMENTS: This study was supported by the Siemens Foundation and a Spar Nord Research Grant. Aalborg Hospital is acknowledged for providing BOTOX ${ }^{\circledR}$. The authors are grateful to Camilla Carlsen, Camilla Sand Andersen, Kamelia Hersini, Line Melgaard, Majbritt Svendsen, Lars Jelstrup Petersen and Dolarose Kulas for assisting in preliminary tests, and Ashir Ejaz and Katarina Åsberg for their technical assistance and guidance. The authors have no conflicts of interest to declare.

\section{REFERENCES}

1. Simpson LL. The origin, structure, and pharmacological activity of botulinum toxin. Pharmacol Rev 1981;33:155-88.

2. Jankovic J. Botulinum toxin in clinical practice. J Neurol Neurosurg Psychiatry 2004;75:951-7.

3. Göbel H, Heinze A, Heinze-Kuhn K, Austermann K. Botulinum toxin $\mathrm{A}$ in the treatment of headache syndromes and pericranial pain syndromes. Pain 2001;91:195-9.

4. Tsui JKC, Jon Stoessl A, Eisen A, Calne S, Calne DB. Double-blind study of botulinum toxin in spasmodic torticollis. Lancet 1986;328:245-7.

5. Brin MF, Fahn S, Moskowitz C, et al. Localized injections of botulinum toxin for the treatment of focal dystonia and hemifacial spasm. Mov Disord 1987;2:237-54.

6. Tugnoli V, Capone JG, Eleopra R, et al. Botulinum toxin type A reduces capsaicin-evoked pain and neurogenic vasodilatation in human skin. Pain 2007;130:76-83.

7. Gazerani P, Pedersen NS, Staahl C, Drewes AM, Arendt-Nielsen L. Subcutaneous botulinum toxin type A reduces capsaicin-induced trigeminal pain and vasomotor reactions in human skin. Pain 2009;141:60-9.

8. Bach-Rojecky L, Lackovic Z. Antinociceptive effect of botulinum toxin type $\mathrm{A}$ in rat model of carrageenan and capsaicin induced pain. Croat Med J 2005;46:201-8.

9. Argoff CE. A focused review on the use of botulinum toxins for neuropathic pain. Clin J Pain 2002;18:S177-81.

10. Ranoux D, Attal N, Morain F, Bouhassira D. Botulinum toxin type A induces direct analgesic effects in chronic neuropathic pain. Ann Neurol 2008;64:274-83.

11. Yuan RY, Sheu JJ, Yu JM, et al. Botulinum toxin for diabetic neuropathic pain: A randomized double-blind crossover trial. Neurology 2009;72:1473-8.

12. Difazio M, Jabbari B. A focused review of the use of botulinum toxins for low back pain. Clin J Pain 2002;18:S155-62.

13. Cheshire WP, Abashian SW, Mann JD. Botulinum toxin in the treatment of myofascial pain syndrome. Pain 1994;59:65-9.

14. Soares A, Andriolo RB, Atallah ÁN, da Silva E. Botulinum toxin for myofascial pain syndromes in adults. Cochrane Database Syst Rev 2012;4:CD007533

15. Ko GD, Whitmore S, Huang D, McDonald R. Effective pain palliation in fibromyalgia syndrome patients with botulinum toxin type-A: Case series of 25. J Musculoskelet Pain 2007;15:55-66.

16. Wu CJ, Lian YJ, Zheng YK, et al. Botulinum toxin type A for the treatment of trigeminal neuralgia: Results from a randomized, doubleblind, placebo-controlled trial. Cephalalgia 2012;32:443-50.

17. Xiao L, Mackey S, Hui H, Xong D, Zhang Q, Zhang D. Subcutaneous injection of botulinum toxin a is beneficial in postherpetic neuralgia. Pain Med 2010;11:1827-33.

18. Silberstein SD, Stark SR, Lucas SM, Christie SN, DeGryse RE, Turkel CC. Botulinum toxin type A for the prophylactic treatment of chronic daily headache: A randomized, double-blind, placebocontrolled trial. Mayo Clin Proc 2005;80:1126-37.

19. Aurora SK, Dodick DW, Turkel CC, et al. OnabotulinumtoxinA for treatment of chronic migraine: Results from the double-blind, randomized, placebo-controlled phase of the PREEMPT 1 trial. Cephalalgia 2010;30:793-80.

20. Dodick DW, Turkel CC, DeGryse RE, et al. OnabotulinumtoxinA for treatment of chronic migraine: Pooled results from the double-blind, randomized, placebo-controlled phases of the PREEMPT clinical program. Headache 2010;50:921-36.

21. Ishikawa H, Mitsui Y, Yoshitomi T, et al. Presynaptic effects of botulinum toxin type A on the neuronally evoked response of albino and pigmented rabbit iris sphincter and dilator muscles. Jpn J Ophthalmol 2000;44:106-9.

22. Bach-Rojecky L, Relja M, Lacković Z. Botulinum toxin type A in experimental neuropathic pain. J Neural Transm 2005;112:215-9.
23. Cui M, Khanijou S, Rubino J, Aoki KR. Subcutaneous administration of botulinum toxin A reduces formalin-induced pain. Pain 2004;107:125-33.

24. Durham PL, Russo AF. Regulation of calcitonin gene-related peptide secretion by a serotonergic antimigraine drug. J Neurosci 1999;19:3423-9.

25. Welch MJ, Purkiss JR, Foster KA. Sensitivity of embryonic rat dorsal root ganglia neurons to Clostridium botulinum neurotoxins. Toxicon 2000;38:245-58.

26. Duggan MJ, Quinn CP, Chaddock JA, et al. Inhibition of release of neurotransmitters from rat dorsal root ganglia by a novel conjugate of a Clostridium botulinum toxin A endopeptidase fragment and Erythrina cristagalli lectin. J Biol Chem 2002;277:34846-52.

27. Aoki KR. Evidence for antinociceptive activity of botulinum toxin type A in pain management. Headache 2003;43:9-15.

28. Dolly O. Synaptic transmission: Inhibition of neurotransmitter release by botulinum toxins. Headache 2003;43:16-24.

29. Durham PL, Cady R, Cady R. Regulation of calcitonin gene-related peptide secretion from trigeminal nerve cells by botulinum toxin type A: Implications for migraine Tterapy. Headache 2004;44:35-43.

30. Aoki KR, Francis J. Updates on the antinociceptive mechanism hypothesis of botulinum toxin A. Parkinsonism Relat Disord 2011;17:S28-33

31. Carlton SM. Peripheral excitatory amino acids. Curr Opin Pharmacol 2001;1:52-6.

32. Carlton SM, Neugebauer V. Peripheral metabotropic glutamate receptors as drug targets for pain relief. Expert Opin Ther Targets 2002;6:349-61.

33. Cairns BE, Gambarota G, Svensson P, Arendt-Nielsen L, Berde C. Glutamate-induced sensitization of rat masseter muscle fibers. Neuroscience 2002;109:389.

34. Ro JY. Contribution of peripheral NMDA receptors in craniofacial muscle nociception and edema formation. Brain Res 2003;979:78-84.

35. Cairns BE, Svensson P, Wang K, et al. Activation of peripheral NMDA receptors contributes to human pain and rat afferent discharges evoked by injection of glutamate into the masseter muscle. J Neurophysiol 2003;90:2098-105.

36. Sarchielli P, Di Filippo M, Nardi K, Calabresi P. Sensitization, glutamate, and the link between migraine and fibromyalgia. Curr Pain Headache Rep 2007;11:343-51.

37. Peres M, Zukerman E, Senne Soares C, Alonso E, Santos B, Faulhaber M. Cerebrospinal fluid glutamate levels in chronic migraine. Cephalalgia 2004;24:735-9.

38. Benveniste H, Drejer J, Schousboe A, Diemer NH. Elevation of the extracellular concentrations of glutamate and aspartate in rat hippocampus during transient cerebral ischemia monitored by intracerebral microdialysis. J Neurochem 1984;43:1369-74.

39. Castrillon EE, Ernberg M, Cairns BE, et al. Interstitial glutamate concentration is elevated in the masseter muscle of myofascial temporomandibular disorder patients. J Orofac Pain 2010;24:350-6.

40. Petersen LS, Kristensen JK, Bülow J. Microdialysis of the interstitial water space in human skin in vivo: Quantitative measurement of cutaneous glucose concentrations. J Invest Dermatol 1992;99:357-60.

41. Alfredson H, Thorsen K, Lorentzon R. In situ microdialysis in tendon tissue: High levels of glutamate, but not prostaglandin E2 in chronic Achilles tendon pain. Knee Surg Sports Traumatol Arthrosc 1999;7:378-81.

42. Schmelz M, Luz O, Averbeck B, Bickel A. Plasma extravasation and neuropeptide release in human skin as measured by intradermal microdialysis. Neurosci Lett 1997;230:117-20.

43. Ueda M, Kuraishi Y, Sugimoto K, Satoh M. Evidence that glutamate is released from capsaicin-sensitive primary afferent fibers in rats: Study with on-line continuous monitoring of glutamate. Neurosci Res 1994;20:231-7.

44. da Silva LB, Kulas D, Karshenas A, et al. Time course analysis of the effects of botulinum neurotoxin type $\mathrm{A}$ on pain and vasomotor responses evoked by glutamate injection into human temporalis muscles. Toxins 2014;6:592-607.

45. Gazerani P, Staahl C, Drewes AM, Arendt-Nielsen L. The effects of botulinum toxin type A on capsaicin-evoked pain, flare, and secondary hyperalgesia in an experimental human model of trigeminal sensitization. Pain 2006;122:315-2.

46. Chaurasia CS, Müller M, Bashaw ED, et al. AAPS-FDA Workshop White Paper: Microdialysis principles, application, and regulatory perspectives. J Clin Pharmacol 2007;47:589-603.

47. Ungerstedt U. Microdialysis - principles and applications for studies in animals and man. J Intern Med 1991;230:365-73. 
48. Whitley E, Ball J. Statistics review 4: Sample size calculations. Critical Care 2002;6:335.

49. Rosendal L, Larsson B, Kristiansen J, et al. Increase in muscle nociceptive substances and anaerobic metabolism in patients with trapezius myalgia: Microdialysis in rest and during exercise. Pain 2004:112:324-3.

50. Lonnroth P, Jansson P, Smith U. A microdialysis method allowing characterization of intercellular water space in humans. Am J Physiol 1987;253:E228-31.

51. LaMotte R, Lundberg L, Torebjörk H. Pain, hyperalgesia and activity in nociceptive $\mathrm{C}$ units in humans after intradermal injection of capsaicin. J Physiol 1992;448:749-64.

52. Holzer P. Capsaicin: Cellular targets, mechanisms of action, and selectivity for thin sensory neurons. Pharmacol Rev 1991;43:143-201.

53. Gazerani P, Au S, Dong X, Kumar U, Arendt-Nielsen L, Cairns BE. Botulinum neurotoxin type A (BoNTA) decreases the mechanical sensitivity of nociceptors and inhibits neurogenic vasodilation in a craniofacial muscle targeted for migraine prophylaxis. Pain 2010;151:606-16.

54. Aoki K. Review of a proposed mechanism for the antinociceptive action of botulinum toxin type A. Neurotoxicology 2005;26:785-93.

55. Dolly J, Aoki K. The structure and mode of action of different botulinum toxins. Eur J Neurol 2006;13:1-9.

56. Humm AM, Pabst C, Lauterburg T, Burgunder J. Enkephalin and aFGF are differentially regulated in rat spinal motoneurons after chemodenervation with botulinum toxin. Exp Neurol 2000;161:361-72.

57. O'Neill J, Brock C, Olesen AE, Andresen T, Nilsson M, Dickenson AH. Unravelling the mystery of capsaicin: A tool to understand and treat pain. Pharmacol Rev 2012;64:939-71.

58. Fiorentino PM, Cairns BE, Hu JW. Development of inflammation after application of mustard oil or glutamate to the rat temporomandibular joint. Arch Oral Biol 1999;44:27-32.

59. Voller B, Sycha T, Gustorff B, et al. A randomized, double-blind, placebo controlled study on analgesic effects of botulinum toxin $\mathrm{A}$. Neurology 2003;61:940-4.

60. Blersch W, Schulte-Mattler WJ, Przywara S, May A, Bigalke H, Wohlfarth K. Botulinum toxin A and the cutaneous nociception in humans: A prospective, double-blind, placebo-controlled, randomized study. J Neurol Sci 2002;205:59-63.

61. Sycha T, Samal D, Chizh B, et al. A lack of antinociceptive or antiinflammatory effect of botulinum toxin A in an inflammatory human pain model. Anesth Analg 2006;102:509-16.

62. Schulte-Mattler WJ, Opatz O, Blersch W, May A, Bigalke H, Wohlfahrt K. Botulinum toxin A does not alter capsaicin-induced pain perception in human skin. J Neurol Sci 2007;260:38-42.

63. Krämer H, Angerer C, Erbguth F, Schmelz M, Birklein F. Botulinum toxin A reduces neurogenic flare but has almost no effect on pain and hyperalgesia in human skin. J Neurol 2003;250:188-93.

64. Flores CM, Leong AS, O Dussor G, Hargreaves KM, Kilo S. Capsaicin-evoked CGRP release from rat buccal mucosa: Development of a model system for studying trigeminal mechanisms of neurogenic inflammation. Eur J Neurosci 2001;14:1113-20.

65. Holzer P. Neurogenic vasodilatation and plasma leakage in the skin. Gen Pharmacol 1998;30:5-11.

66. De Biasi S, Rustioni A. Glutamate and substance P coexist in primary afferent terminals in the superficial laminae of spinal cord. Proc Natl Acad Sci 1988;85:7820-4.

67. Caterina MJ, Schumacher MA, Tominaga M, Rosen TA, Levine JD, Julius D. The capsaicin receptor: A heat-activated ion channel in the pain pathway. Nature 1997;389:816-24.

68. Brain S, Williams T, Tippins J, Morris H, MacIntyre I. Calcitonin gene-related peptide is a potent vasodilator Nature 1985;313:54-6

69. Weidner C, Klede M, Rukwied R, et al. Acute effects of substance P and calcitonin gene-related peptide in human skin - a microdialysis study. J Invest Dermatol 2000;115:1015-20.

70. Xu H, Ramsey IS, Kotecha SA, et al. TRPV3 is a calcium-permeable temperature-sensitive cation channel. Nature 2002;418:181-6.

71. Vuksanović V, Sheppard LW, Stefanovska A. Nonlinear relationship between level of blood flow and skin temperature for different dynamics of temperature change. Biophys J 2008;94:L78-80. 


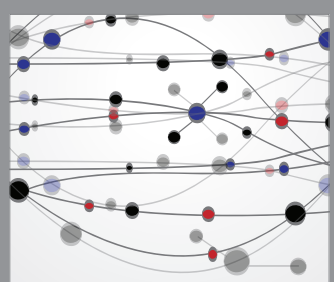

The Scientific World Journal
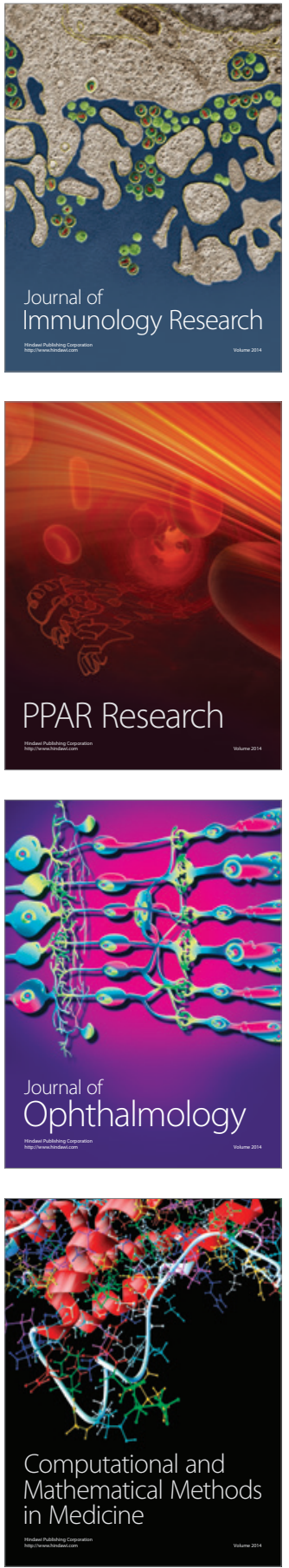

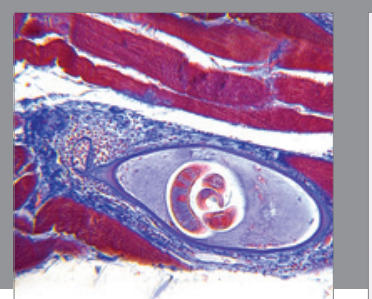

Gastroenterology Research and Practice

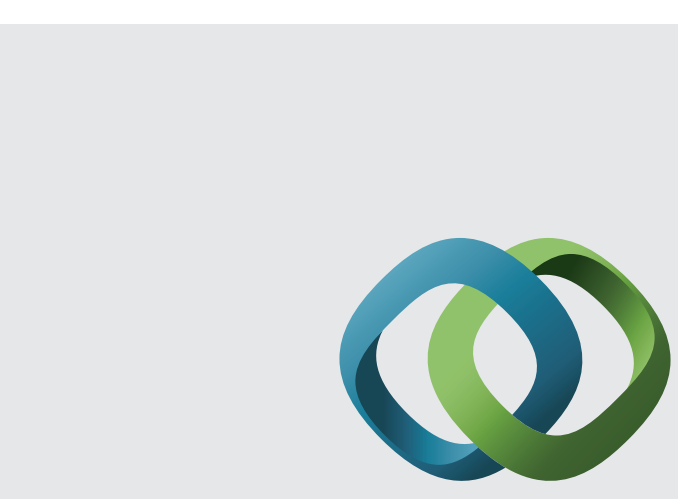

\section{Hindawi}

Submit your manuscripts at

http://www.hindawi.com
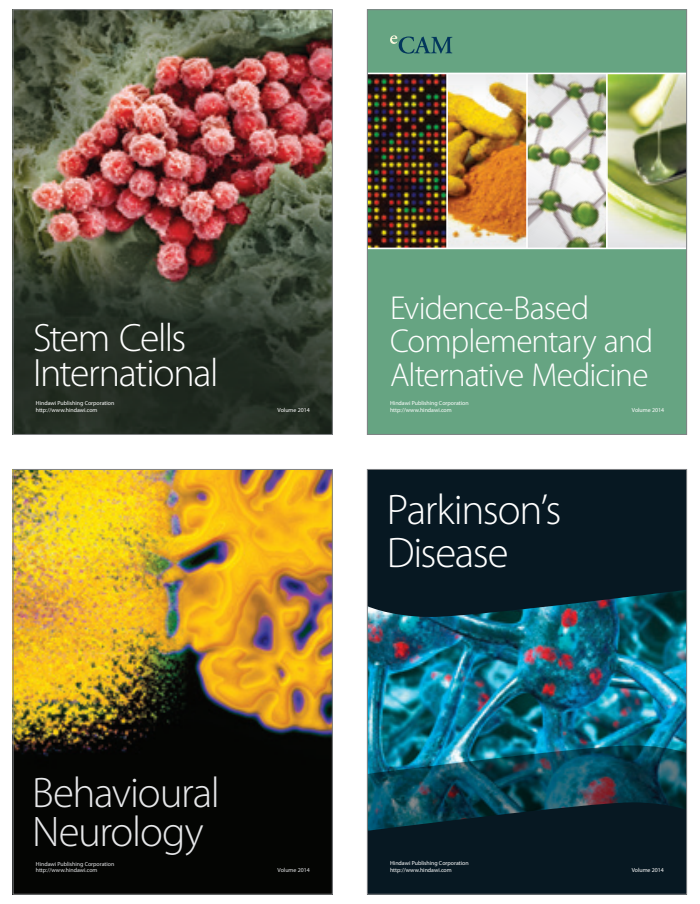
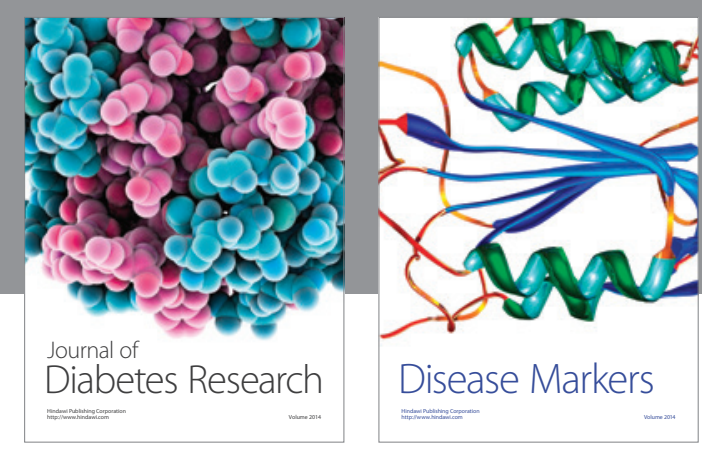

Disease Markers
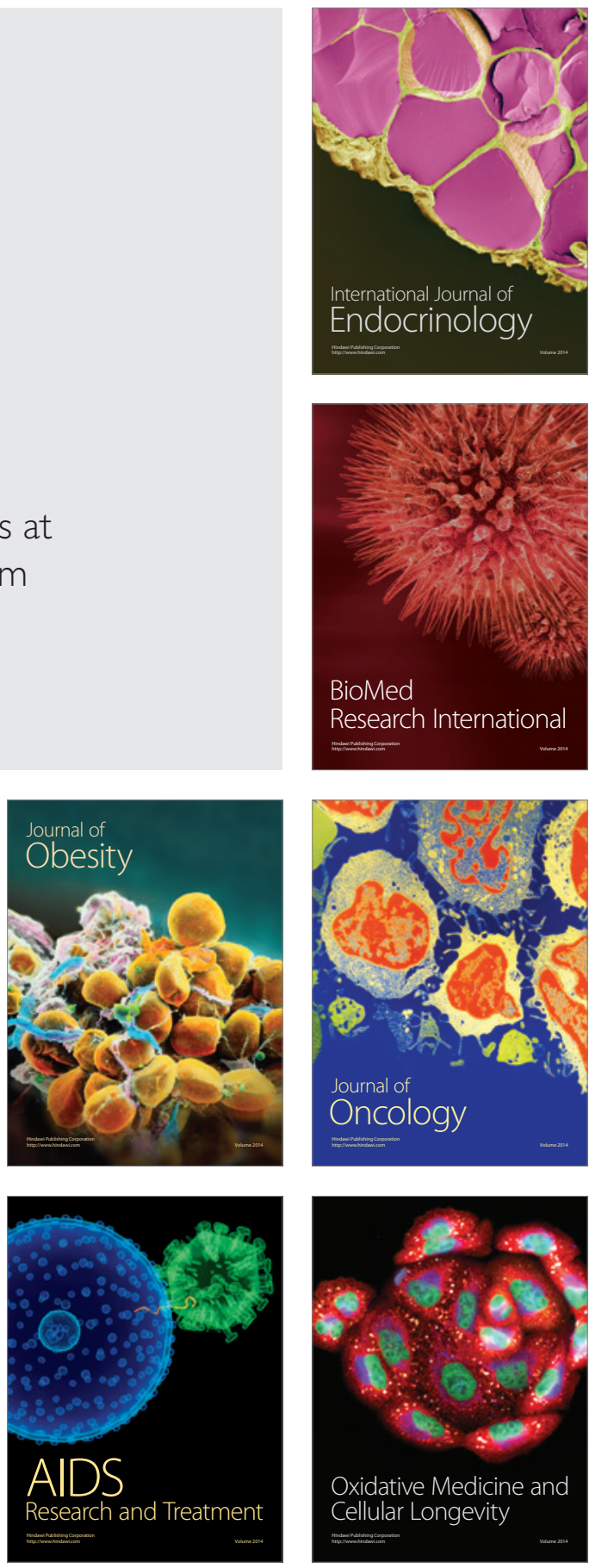